\title{
Predictors of Mental Health Status among Older United States Adults with Pain
}

\author{
David R. Axon *(D) and Jonathan Chien \\ College of Pharmacy, University of Arizona, Tucson, AZ 85721, USA; jchien@pharmacy.arizona.edu \\ * Correspondence: axon@pharmacy.arizona.edu; Tel.: +1-520-621-5961
}

check for

updates

Citation: Axon, D.R.; Chien, J. Predictors of Mental Health Status among Older United States Adults with Pain. Behav. Sci. 2021, 11, 23. https://doi.org/10.3390/bs11020023

Academic Editors: Heidi Ewen and Katherina Nikzad-Terhune

Received: 16 December 2020

Accepted: 3 February 2021

Published: 5 February 2021

Publisher's Note: MDPI stays neutral with regard to jurisdictional claims in published maps and institutional affiliations.

Copyright: (c) 2021 by the authors. Licensee MDPI, Basel, Switzerland. This article is an open access article distributed under the terms and conditions of the Creative Commons Attribution (CC BY) license (https:/ / creativecommons.org/licenses/by/ $4.0 /)$.

\begin{abstract}
Poor mental health is common among older adults with pain, resulting in high economic burden and impaired quality of life. This retrospective, cross-sectional database study aimed to identify characteristics associated with good mental health status among United States (US) adults aged $\geq 50$ years with self-reported pain in the last four weeks using a weighted sample of 2017 Medical Expenditure Panel Survey data. Hierarchical multivariable logistic regression models were used to identify statistically significant predictors of good (versus poor) perceived mental health status. From a weighted population of 57,074,842 individuals, $85.5 \%$ ( $95 \%$ confidence interval $(\mathrm{CI})=84.4 \%, 86.7 \%$ ) had good perceived mental health. Good mental health was associated most strongly with physical health status (adjusted odds ratio $(\mathrm{AOR})=9.216,95 \% \mathrm{CI}=7.044,12.058)$. Employed individuals were 1.7 times more likely to report good mental health versus unemployed ( $\mathrm{AOR}=1.715,95 \% \mathrm{CI}=1.199$, 2.452). Individuals who had completed less than high school education ( $\mathrm{AOR}=0.750,95 \% \mathrm{CI}=0.569$, 0.987 ) or who reported having a limitation ( $\mathrm{AOR}=0.513,95 \% \mathrm{CI}=0.384,0.684$ ) were less likely to report good mental health. These key characteristics can be utilized to predict mental health status, which may be investigated to better manage concurrent pain and poor mental health.
\end{abstract}

Keywords: mental health; pain; health care surveys; older adults

\section{Introduction}

The International Association for the Study of Pain (IASP) defines pain as: "an unpleasant sensory and emotional experience associated with, or resembling that associated with, actual or potential tissue damage" [1]. The ambiguous and dynamic nature of pain makes qualifying, quantifying, and managing pain difficult [2], and pain is the highest-reported cause of sought medical attention in the United States (US) [3].

The estimated prevalence of pain in US adults ranges from 100 to 126 million [4,5], and perpetuates in older adults discriminately; the prevalence of pain in older adults (aged >60 years) has been shown to reach rates of 55\% [6]. As a result of economic, social, medical, and public health advancements, the percentage of older adults continues to rise in congruency with the number of patients with pain [7]. The total economic cost of pain is estimated to range from USD 560 to USD 635 billion per year in 2010 dollars [4,8]. In addition to economic consequences, pain has been associated with worse health outcomes such as disability, more frequent physician visits, and an overall impaired quality of life [4,9]. Pain is associated with differences in various personal characteristics, including older age $[6,10]$, gender [11,12], ethnicity [5], race [13], socioeconomic class [14], education status [15], employment status [16], comorbidities [17], smoking and alcohol consumption [18,19], and exercise $[20,21]$.

There is a strong, positive association between the physical symptoms of pain and the psychological symptoms, partially explained by related, interlinked neural pathways [22,23]. In addition, patients who report existing physical problems are more likely to report an anxiety/depressive disorder, commit suicide, and smoke cigarettes [23]. Inversely, patients with existing mental health disorders are more likely to report a greater number of physical problems [24]. Pain is also associated with poor mental health regardless 
of pain etiology [25]. A study by the World Health Organization found patients who reported pain were at a $400 \%$ increased disposition to anxiety or depressive disorders, which was consistent across cultures [26]. Despite the discovery of several drug classes that simultaneously manage pain and mental health disorders (serotonin-norepinephrine reuptake inhibitors, anticonvulsants, etc.), pain remains uncontrolled for many, and the prevalence and consequences remain consistently high $[4,9,27]$.

In addition to pharmacological therapy, behavioral and lifestyle modification therapy may be necessary to optimize therapeutic treatments [23,28]. With the likelihood of relapsing and reoccurring mental health disorders, such as depression, increasing in older adults [29], it is important to investigate predictors of mental health status in a variety of populations. In particular, the factors associated with comorbid mental illness and pain in older adults (age $\geq 50$ ) are not well understood. This information is important to minimize the economic and medical consequences arising from non-optimized management of pain and mental health. Therefore, this study sought to identify the predictors of good mental health (versus poor mental health) among a nationally representative sample from the Medical Expenditure Panel Survey (MEPS) dataset of US adults aged $\geq 50$ years with pain in the past four weeks.

\section{Materials and Methods}

\subsection{MEPS Data and Study Design}

MEPS is conducted by the Agency for Healthcare Research and Quality (AHRQ) in multiple interview rounds over a two-year period. MEPS uses a sub-sample of the previous years' National Health Interview Survey (NHIS) and can produce nationally representative estimates of the non-institutionalized US population by oversampling disabled and minority groups. The MEPS household component (MEPS-HC), one of the key MEPS components, contains self-reported data about each household member surveyed, including (but not limited to): demographic data, health care expenditure and utilization data, health condition data, and health status data [30]. This cross-sectional, retrospective study used the 2017 MEPS full-year consolidated data file (the most current data available at the time of the study) [31]. MEPS respondents provide oral informed consent to voluntarily participate in the survey. The University of Arizona Institutional Review Board approved this study (protocol number 2006721124).

\subsection{Eligibility}

Study participants were included in the analysis if they were alive for the full calendar year, $\geq 50$ years of age, and reported having pain in the last four weeks. Pain was determined based on responses to the question "During the past four weeks, pain interfered with normal work outside the home and housework" of a little bit, moderately, quite a bit, or extremely [32,33].

\subsection{Dependent Variable}

The dependent variable in this study was perceived mental health status, categorized as good or poor. These categories were developed based on responses to the question that asked survey participants to rate their mental health as excellent, very good, good, fair, or poor. For the purposes of this study, responses of excellent, very good, and good were classified as good mental health, and fair or poor as poor mental health [32,33].

\subsection{Independent Variables}

The independent variables in this study were grouped according to Andersen's Behavioral Model of Health Services Use, as described below [34].

Predisposing factors consisted of: age (in years, 50-64, $\geq 65$ ); gender (male, female); race (white, other); and ethnicity (Hispanic, non-Hispanic).

Enabling factors consisted of: marital status (married, other); poverty status $(<200 \%$ federal level, $\geq 200 \%$ federal poverty level); education status (less than high school, com- 
pleted high school, more than high school); employment status (employed, unemployed); and health insurance status (private, public, uninsured).

Need factors included: limitations (yes, no); number of chronic conditions from the following list: angina, arthritis, asthma, cancer, chronic bronchitis, coronary heart disease, diabetes, joint pain, emphysema, hypercholesterolemia, hypertension, myocardial infarction, other unspecified heart disease, stroke $(0,1,2,3,4, \geq 5)$; pain (little/moderate, quite a bit/extreme); and perceived physical health condition (excellent/very good/good, fair/poor).

External environmental and personal health practice factors were: region (Northeast, Midwest, South, West); regular exercise (yes, no); and smoking status (yes, no) [32,33].

\subsection{Data Analysis}

Using SAS University Edition (SAS institute Inc., Cary, NC, USA), the characteristics of study participants who perceived their mental health to be good with those who perceived their mental health to be poor were compared via chi-square tests. Then, hierarchical logistic regression models were used to assess statistically significant predictors of good perceived mental health status, with poor perceived mental health status serving as the reference group. The first model assessed predisposing factors, and an additional group of characteristics was added to each subsequent model until the final model was reached that included predisposing, enabling, need, and external environmental and personal health practice factors. The a priori alpha level was 0.05 .

\section{Results}

This study included a total of 5076 study participants, of which 4225 perceived their mental health as good, while 851 perceived their mental health as poor. This translated to a weighted population of $57,074,842$ individuals, of which $85.5 \%$ (95\% confidence interval $(\mathrm{CI})=84.4 \%, 86.7 \%)$ perceived their mental health as good, while $14.5 \%(95 \% \mathrm{CI}=13.5 \%$, $15.6 \%$ ) perceived their mental health as poor.

The majority of individuals in the study had the following characteristics: aged $\geq 65$ years, female, white race, non-Hispanic, married, $\geq 200 \%$ federal poverty level, completed more than high school education, unemployed, private health insurance coverage, limitations, $\geq 4$ total chronic health conditions, little/moderate pain, excellent/very good/good physical health, no regular exercise, and non-smokers. The most common region was the South. There were significant differences between individuals who reported good mental health and those who reported poor mental health for all characteristics $(p<0.05)$ except age $(p=0.8267)$, gender $(p=0.0997)$, and region $(p=0.9556)$. For further details on the characteristics of study participants, see Table 1.

The strongest predictor of good mental health status was physical health status (adjusted odds ratio $(\mathrm{AOR})=9.216,95 \% \mathrm{CI}=7.044,12.058)$. Individuals who were employed were approximately 1.7 times more likely to report good mental health than those who were unemployed $(\mathrm{AOR}=1.715,95 \% \mathrm{CI}=1.199,2.452)$. Compared to those who had completed more than high school education, individuals who had completed less than high school education were less likely to report good mental health (AOR $=0.750,95 \% \mathrm{CI}=0.569$, 0.987). Similarly, compared to individuals who did not report having a limitation, those who did have a limitation were less likely to report good mental health ( $\mathrm{AOR}=0.513$, $95 \% \mathrm{CI}=0.384,0.684$ ). The logistic regression model had a c-statistic of 0.844 and a Wald statistic of $<0.0001$. For further details on the logistic regression results, see Table 2 . 
Table 1. Characteristics of older United States adults (age $\geq 50$ years) with self-reported pain in the past four weeks, stratified by good and poor perceived mental health status.

\begin{tabular}{|c|c|c|c|}
\hline Factors & $\begin{array}{c}\text { Good Perceived Mental Health Status } \\
\text { (Weighted N }=48,820,087) \\
\text { Weighted Percent }(95 \% \text { Confidence } \\
\text { Interval) }\end{array}$ & $\begin{array}{c}\text { Poor Perceived Mental Health Status } \\
\text { (Weighted N }=8,254,755) \\
\text { Weighted Percent }(95 \% \text { Confidence } \\
\text { Interval) }\end{array}$ & $p$ \\
\hline \multicolumn{4}{|l|}{ Predisposing: } \\
\hline \multicolumn{4}{|l|}{ Age (years) } \\
\hline $50-64$ & 85.4 (83.9-86.9) & $14.6(13.1-16.1)$ & \multirow[t]{2}{*}{0.8267} \\
\hline$\geq 65$ & $85.7(84.0-87.4)$ & $14.3(12.6-16.0)$ & \\
\hline \multicolumn{4}{|l|}{ Gender } \\
\hline Male & 86.5 (84.9-88.1) & $13.5(11.9-15.1)$ & \multirow[t]{2}{*}{0.0997} \\
\hline Female & $84.8(83.3-86.2)$ & $15.2(13.8-16.7)$ & \\
\hline \multicolumn{4}{|l|}{ Race } \\
\hline White & $86.5(85.2-87.7)$ & $13.5(12.3-14.8)$ & \multirow[t]{2}{*}{0.0004} \\
\hline Other & $81.6(79.1-84.1)$ & $18.4(15.9-20.9)$ & \\
\hline \multicolumn{4}{|l|}{ Ethnicity } \\
\hline Hispanic & $80.4(77.0-83.7)$ & $19.6(16.3-23.0)$ & \multirow[t]{2}{*}{0.0004} \\
\hline Non-Hispanic & $86.1(84.9-87.3)$ & $13.9(12.7-15.1)$ & \\
\hline \multicolumn{4}{|l|}{ Enabling: } \\
\hline \multicolumn{4}{|l|}{ Marital status } \\
\hline Married & $88.1(86.7-89.6)$ & $11.9(10.4-13.3)$ & \multirow[t]{2}{*}{$<0.0001$} \\
\hline Other & $82.1(80.3-83.9)$ & $17.9(16.1-19.7)$ & \\
\hline \multicolumn{4}{|l|}{ Poverty status } \\
\hline$<200 \%$ federal level & $75.6(73.3-77.9)$ & $24.4(22.1-26.7)$ & \multirow[t]{2}{*}{$<0.0001$} \\
\hline$\geq 200 \%$ federal level & $90.3(88.9-91.6)$ & $9.7(8.4-11.1)$ & \\
\hline \multicolumn{4}{|l|}{ Education status } \\
\hline Less than high school & $75.1(71.8-78.5)$ & $24.9(21.5-28.2)$ & \multirow{3}{*}{$<0.0001$} \\
\hline Completed high school & $85.2(83.4-86.9)$ & $14.8(13.1-16.6)$ & \\
\hline More than high school & 89.4 (87.9-90.8) & $10.6(9.2-12.1)$ & \\
\hline \multicolumn{4}{|l|}{ Employment status } \\
\hline Employed & $93.7(92.4-95.1)$ & $6.3(4.9-7.6)$ & \multirow[t]{2}{*}{$<0.0001$} \\
\hline Unemployed & $80.3(78.6-82.0)$ & $19.7(18.0-21.4)$ & \\
\hline \multicolumn{4}{|l|}{ Health insurance status } \\
\hline Private & $91.3(90.1-92.6)$ & $8.7(7.4-9.9)$ & \multirow{3}{*}{$<0.0001$} \\
\hline Public & $75.9(73.5-78.2)$ & $24.1(21.8-26.5)$ & \\
\hline Uninsured & 82.1 (75.4-88.7) & $17.9(11.3-24.6)$ & \\
\hline \multicolumn{4}{|l|}{ Need: } \\
\hline \multicolumn{4}{|l|}{ Limitation } \\
\hline Yes & $77.5(75.5-79.5)$ & $22.5(20.5-24.5)$ & \multirow[t]{2}{*}{$<0.0001$} \\
\hline No & $93.8(92.8-94.8)$ & $6.2(5.2-7.2)$ & \\
\hline Number of chronic conditions & & & \\
\hline 0 & $93.0(89.8-96.2)$ & $7.0(3.8-10.2)$ & \\
\hline 1 & $90.7(88.0-93.3)$ & $9.3(6.7-12.0)$ & \\
\hline 2 & $90.0(87.5-92.5)$ & $10.0(7.5-12.5)$ & $<0.0001$ \\
\hline 3 & $88.4(86.0-90.7)$ & $11.6(9.3-14.0)$ & \\
\hline 4 & $85.8(83.1-88.6)$ & $14.2(11.4-16.9)$ & \\
\hline$\geq 5$ & $79.1(76.9-81.3)$ & $20.9(18.7-23.1)$ & \\
\hline Pain & & & \\
\hline Little/moderate & $90.2(89.1-91.3)$ & $9.8(8.7-10.9)$ & $<0.0001$ \\
\hline Quite a bit/extreme & $71.5(68.6-74.4)$ & $28.5(25.6-31.4)$ & \\
\hline Perceived physical health statu & & & \\
\hline Excellent/very good/good & $95.4(94.5-96.2)$ & $4.6(3.8-5.5)$ & $<0.0001$ \\
\hline Fair/poor & $58.9(55.7-62.1)$ & $41.1(37.9-44.3)$ & \\
\hline
\end{tabular}


Table 1. Cont.

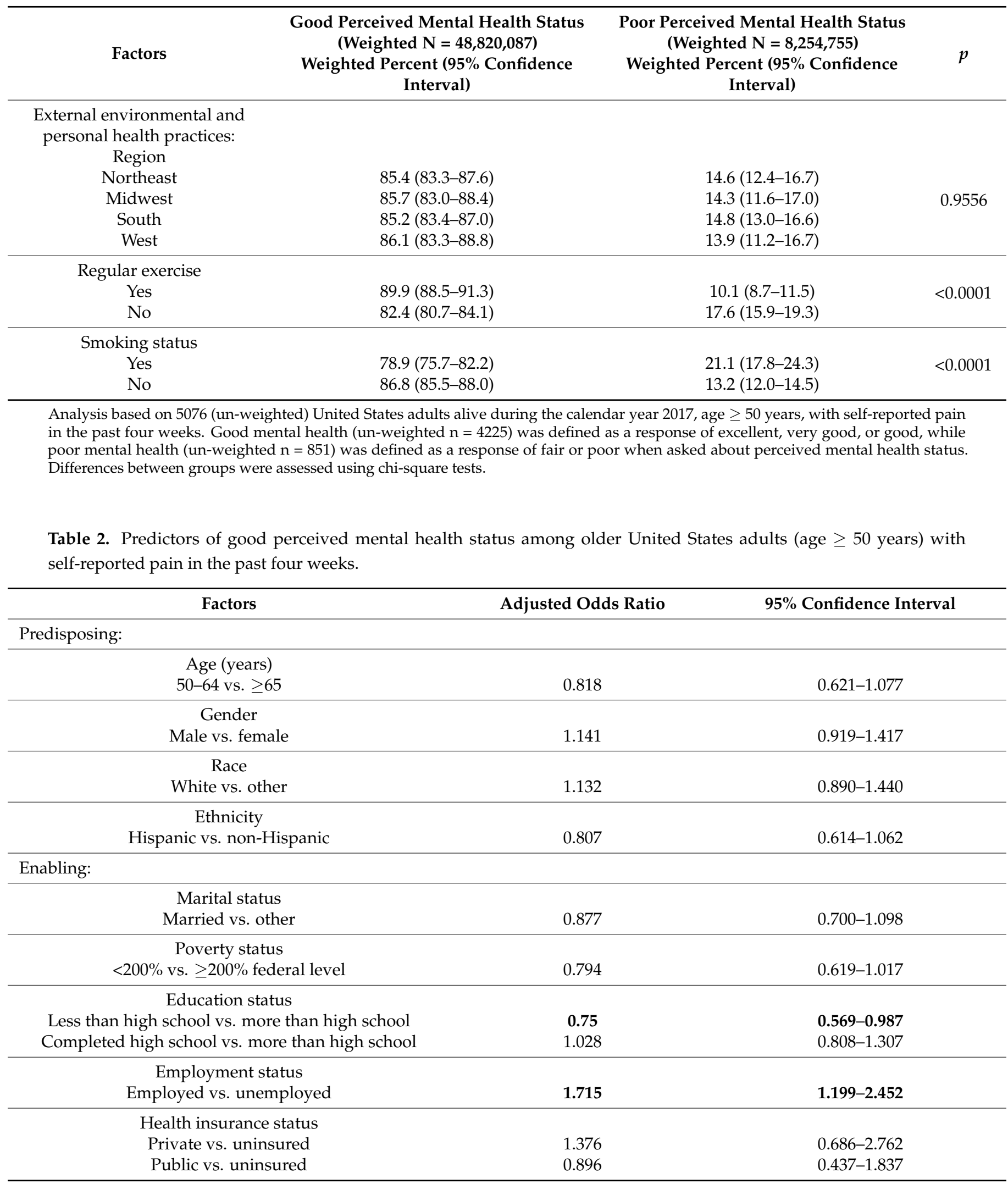


Table 2. Cont.

\begin{tabular}{|c|c|c|}
\hline Factors & Adjusted Odds Ratio & 95\% Confidence Interval \\
\hline \multicolumn{3}{|l|}{ Need: } \\
\hline \multicolumn{3}{|l|}{ Limitation } \\
\hline Yes vs. no & 0.513 & $0.384-0.684$ \\
\hline \multicolumn{3}{|l|}{ Number of chronic conditions } \\
\hline 0 vs. $\geq 5$ & 0.938 & $0.483-1.822$ \\
\hline 1 vs. $\geq 5$ & 0.683 & $0.431-1.083$ \\
\hline 2 vs. $\geq 5$ & 1.102 & $0.742-1.636$ \\
\hline 3 vs. $\geq 5$ & 0.922 & $0.670-1.268$ \\
\hline 4 vs. $\geq 5$ & 0.892 & $0.646-1.230$ \\
\hline \multicolumn{3}{|l|}{ Pain } \\
\hline Little/moderate vs. quite a bit/extreme & 1.121 & $0.875-1.435$ \\
\hline Perceived physical health status & & \\
\hline Excellent/very good/good vs. fair/poor & 9.216 & 7.044-12.058 \\
\hline \multicolumn{3}{|l|}{ External environmental and personal health practices: } \\
\hline \multicolumn{3}{|l|}{ Region } \\
\hline Northeast vs. West & 0.955 & $0.664-1.374$ \\
\hline Midwest vs. West & 0.923 & $0.624-1.366$ \\
\hline South vs. West & 1.19 & $0.851-1.665$ \\
\hline \multicolumn{3}{|l|}{ Regular exercise } \\
\hline Yes vs. no & 1.146 & $0.917-1.433$ \\
\hline \multicolumn{3}{|l|}{ Smoking status } \\
\hline Yes vs. no & 0.875 & $0.662-1.157$ \\
\hline
\end{tabular}

Analysis based on 5076 (un-weighted) United States adults alive during the calendar year 2017, age $\geq 50$ years, with self-reported pain in the past four weeks. Good mental health (un-weighted $n=4225$ ) was defined as a response of excellent, very good, or good, while poor mental health (un-weighted $\mathrm{n}=851$; reference group) was defined as a response of fair or poor when asked about perceived mental health status. Bold indicates the variable was a predictor of perceived health status.

\section{Discussion}

While past studies have evaluated the relationship between pain and mental health status, the current study used a nationally representative dataset (i.e., MEPS) to identify predictors of mental health status among older adults with pain. This study identified four statistically significant predictors of mental health status-perceived physical health status, limitation status, employment status, and education level-that demonstrate potential value as investigational, therapeutic lifestyle interventions, for older adults with pain. Such predictive variables may be important not just to help address mental health concerns among older adults with pain, but also emphasize the substantial suicide risk among these patients that must be managed and warrants further research [35-43].

\subsection{Perceived Physical Health Status}

Given that pain is a function of physical health status, it seems intuitive that perceived physical health status was associated with mental health status among older adults with pain in this study. Interestingly, in this study, perceived physical health status was the strongest predictor of good mental health status. Previous studies have found similar findings. For example, one study found that poor self-rated health in older adults was associated with "emotional problems", suggesting correlates of health status may identify patients requiring therapeutic intervention [44]. However, the hypothesized bidirectional association between physical and mental health status may imply that patients with poor physical health require additional preemptive support for the prevention and treatment of mental illness and its secondary complications [22,23]. This is further supported by the inflammation hypothesis, which suggests that mental health decline related to neuroinflammation (facilitated by chronic inflammatory cytokine production), intrinsic to older adults, 
is exacerbated by pain related to multiple other etiologies [29]. Furthermore, Ohrnberger et al. also found that past physical health was associated with a direct and indirect impact on mental health status-primarily mediated by physical activity [45].

\subsection{Limitation Status}

In the current study, older adults with pain who concurrently reported a limitation were more likely to report poor mental health. Townley et al. found similar findings; patients with a marked limitation status exhibited decreased community participation, demonstrating that barriers to participation may exacerbate reclusiveness and mental illness [46]. Pain (as a surrogate for limitation status) has been shown to serve as a barrier to effective mental health treatment, perpetuating poor mental health [47]. Thielke et al. found that older adults with pain exhibited a diminished response to depression therapy. This raises the question as to whether limitation status is primarily a function of physiology or psychology [48]. While limitation status may be influenced by both, comparing physical therapy (PT) to cognitive behavioral therapy (CBT), Karp et al. found PT to produce a greater response than CBT (47.5\% vs. $20.5 \%)$ in preventing depression and anxiety in older adults with osteoarthritis [49]. This may suggest the success of the treatment to be closely related to physiologic intervention during cases of comorbid pain and poor mental health. While current and past research reinforce the importance of providing access to rehabilitative care, in older patients with poor mental and physical health status, additional findings of this study also suggest that environmental predictors and modification may promote good mental health status.

\subsection{Employment Status}

The results of this study show that older adults with pain who reported employment were more likely to report good mental health. These findings are consistent with a previous study that found employment was associated with improvements in quality of life and mental health status [47]. This may be in part due to an increased prevalence in daytime sleepiness in unemployed individuals, increasing the risk of pain and poor mental health [50]. Furthermore, past research has found that older adults, especially those who did not have formal education training, when unable to work, were more likely to develop significant out-of-pocket health expenditures and become dependent on others for financial support [51]. In turn, this may lead to feelings of indebtedness and have been associated with a higher susceptibility to developing depression [51]. Future research investigating the financial situation of older adults with pain and poor mental health is warranted. While pain can be limiting to physical activity, creating and providing jobs (that are potentially uninhibited by physical activity) to older adults with pain may support positive mental health by promoting opportunities for socialization, cognitive stimulation, and feelings of value to improve overall quality of life $[44,52,53]$. However, it is important to recognize an additional potential barrier to employment-education status.

\subsection{Education Status}

The current study also found that older adults with pain, who also did not complete a high school level education, were associated with a greater likelihood of reporting poor mental health. Previous research has found that educational attainment and early education have significant positive neuropsychological benefits, which prevent cognitive decline [54]. Furthermore, this may indicate that older adults may require additional educational opportunities for improving overall knowledge and health literacy. Poor health literacy may arise from a limited education status and promote a poor understanding of self-care and pain management. Another study found that poor health literacy was associated with both poor physical and mental health [55]. Ultimately, limited education may perpetuate poor health literacy, mistreated pain, and poor mental health. 


\subsection{Limitations and Future Work}

The limitations of this study include those intrinsic to self-reported and secondary data analysis, in particular recall bias from survey participants, although the frequent MEPS interviews (reoccurring every 4 to 5 months) help reduce this risk. The study design was unable to determine a cause-and-effect relationship yet was able to demonstrate a statistical association between four predictor variables and mental health status. The strength of the study was the adjusted MEPS design, which provided a large nationally representative sample for analysis and enhanced generalizability of the findings. Based on the findings of this study, future research should investigate whether interventions to address the four factors associated with mental health status can lead to changes in mental health status. This may involve a longitudinal analysis to determine the trajectory of comorbid pain and mental health status.

\section{Conclusions}

In summary, this is the first study to evaluate predictors of mental health status in older adults on a national level using data from the 2017 MEPS dataset. Four statistically significant predictors of mental health status were found: [1] perceived physical health status, [2] limitation status, [3] employment status, and [4] education level. Positive physical health status was found to have the strongest level of association with positive mental health. These findings indicate important characteristics to address to help improve mental health status among older adults with pain, which may help emphasize a shift to predictive medicine rather than secondary prevention for mental health conditions. There is a need for future longitudinal studies in order to determine causality.

Author Contributions: Conceptualization, D.R.A. and J.C.; methodology, D.R.A.; software, D.R.A.; validation, D.R.A. and J.C.; formal analysis, D.R.A.; investigation, D.R.A.; resources, D.R.A.; data curation, D.R.A.; writing-original draft preparation, D.A and J.C.; writing-review and editing, D.R.A.; visualization, D.A and J.C.; supervision, D.R.A.; project administration, D.R.A.; funding acquisition, D.R.A. All authors have read and agreed to the published version of the manuscript.

Funding: This research received no external funding.

Institutional Review Board Statement: The University of Arizona Institutional Review Board approved this study (protocol number 2006721124).

Informed Consent Statement: Not applicable.

Data Availability Statement: The data presented in this study are available on request from the corresponding author.

Conflicts of Interest: David R. Axon has received research funding from the American Association of Colleges of Pharmacy, Arizona Department of Health Services, Pharmacy Quality Alliance, Merck \& Co., and Tabula Rasa HealthCare Group outside of this study.

\section{References}

1. Raja, S.N.; Carr, D.B.; Cohen, M.; Finnerup, N.B.; Flor, H.; Gibson, S.; Keefe, F.J.; Mogil, J.S.; Ringkamp, M.; Sluka, K.A.; et al. The revised International Association for the Study of Pain definition of pain: Concepts, challenges, and compromises. Pain 2020, 161, 1976-1982. [CrossRef]

2. Gregory, J.; McGowan, L. An examination of the prevalence of acute pain for hospitalised adult patients: A systematic review. J. Clin. Nurs. 2016, 25, 583-598. [CrossRef]

3. Tompkins, D.A.; Hobelmann, J.G.; Compton, P. Providing chronic pain management in the "Fifth Vital Sign" Era: Historical and treatment perspectives on a modern-day medical dilemma. Drug Alcohol. Depend. 2017, 173, S11-S21. [CrossRef]

4. Institute of Medicine (US) Committee on Advancing Pain Research, Care and Education. Relieving Pain in America: A Blue-print for Transforming Prevention, Care, Education, and Research; National Academies Press (US): Washington, DC, USA, 2011.

5. Nahin, R.L. Estimates of Pain Prevalence and Severity in Adults: United States, 2012. J. Pain 2015, 16, 769-780. [CrossRef]

6. Jakobsson, U. The epidemiology of chronic pain in a general population: Results of a survey in southern Sweden. Scand. J. Rheumatol. 2010, 39, 421-429. [CrossRef]

7. United Nations. Statistical Papers-United Nations (Ser. A), Population and Vital Statistics Report. In World Population Ageing 2015; United Nations: New York, NY, USA, 2017. [CrossRef] 
8. Gaskin, D.J.; Richard, P. The Economic Costs of Pain in the United States. J. Pain 2012, 13, 715-724. [CrossRef]

9. Axon, D.R.; Bhattacharjee, S.; Warholak, T.L.; Slack, M.K. Xm2Scores for Estimating Total Exposure to Multimodal Strategies Identified by Pharmacists for Managing Pain: Validity Testing and Clinical Relevance. Pain Res. Manag. 2018, $2018,1-11$. [CrossRef]

10. Shmagel, A.; Foley, R.; Ibrahim, H. Epidemiology of Chronic Low Back Pain in US Adults: Data from the 2009-2010 National Health and Nutrition Examination Survey. Arthritis Rheum. 2016, 68, 1688-1694. [CrossRef]

11. Templeton, K.J. Sex and Gender Issues in Pain Management. J. Bone Jt. Surg. 2020, 102, 32-35. [CrossRef]

12. García-Esquinas, E.; Rodriguez-Sanchez, I.; Ortolá, R.; Lopez-Garcia, E.; Caballero, F.F.; Rodríguez-Mañas, L.; Banegas, J.R.; Rodríguez-Artalejo, F. Gender Differences in Pain Risk in Old Age: Magnitude and Contributors. In Mayo Clinic Proceedings; Elsevier BV: Amsterdam, The Netherlands, 2019; Volume 94, pp. 1707-1717.

13. Macfarlane, G.J.; Beasley, M.; Smith, B.H.; Jones, G.T.; Macfarlane, T.V. Can large surveys conducted on highly selected populations provide valid information on the epidemiology of common health conditions? An analysis of UK Biobank data on musculoskeletal pain. Br. J. Pain 2015, 9, 203-212. [CrossRef]

14. Mechlin, B. Lower socioeconomic status is associated with rating experimental pain as more intense. J. Pain 2012,13 , S52. [CrossRef]

15. Lanitis, S.; Mimigianni, C.; Raptis, D.; Sourtse, G.; Sgourakis, G.; Karaliotas, C. The Impact of Educational Status on the Postoperative Perception of Pain. Korean J. Pain 2015, 28, 265-274. [CrossRef]

16. Watson, P.J.; Booker, C.K.; Moores, L.; Main, C.J. Returning the chronically unemployed with low back pain to employment. Eur. J. Pain 2004, 8, 359-369. [CrossRef]

17. Dominick, C.H.; Blyth, F.M.; Nicholas, M. Unpacking the burden: Understanding the relationships between chronic pain and comorbidity in the general population. Pain 2012, 153, 293-304. [CrossRef] [PubMed]

18. Orhurhu, V.J.; Pittelkow, T.P.; Hooten, W.M. Prevalence of smoking in adults with chronic pain. Tob. Induc. Dis. 2015, 13, 17. [CrossRef]

19. Alford, D.P.; German, J.S.; Samet, J.H.; Cheng, D.M.; Lloyd-Travaglini, C.A.; Saitz, R. Primary Care Patients with Drug Use Report Chronic Pain and Self-Medicate with Alcohol and Other Drugs. J. Gen. Intern. Med. 2016, 31, 486-491. [CrossRef] [PubMed]

20. Moseng, T.; Dagfinrud, H.; Smedslund, G.; Østerås, N. The importance of dose in land-based supervised exercise for people with hip osteoarthritis. A systematic review and meta-analysis. Osteoarthr. Cartil. 2017, 25, 1563-1576. [CrossRef]

21. Mills, S.E.; Nicolson, K.P.; Smith, B.H. Chronic pain: A review of its epidemiology and associated factors in population-based studies. Br. J. Anaesth. 2019, 123, e273-e283. [CrossRef]

22. Watson, D.; Pennebaker, J.W. Health complaints, stress, and distress: Exploring the central role of negative affectivity. Psychol. Rev. 1989, 96, 234-254. [CrossRef] [PubMed]

23. Hooten, W.M. Chronic Pain and Mental Health Disorders. Mayo Clin. Proc. 2016, 91, 955-970. [CrossRef]

24. Kroenke, K. Physical symptoms in primary care. Predictors of psychiatric disorders and functional impairment. Arch. Fam. Med. 1994, 3, 774-779. [CrossRef]

25. Katon, W.; Sullivan, M.; Walker, E. Medical Symptoms without Identified Pathology: Relationship to Psychiatric Disorders, Childhood and Adult Trauma, and Personality Traits. Ann. Intern. Med. 2001, 134, 917-925. [CrossRef]

26. Gureje, O.; Simon, G.E.; Von Korff, M. A cross-national study of the course of persistent pain in primary care. Pain 2001, 92, 195-200. [CrossRef]

27. LaLonde, L.; Jouini, G.; Martin, E.; Perreault, S.; Berbiche, D.; Lussier, D.; Éveline, H.; Choinière, M. Pharmacotherapeutic management of chronic noncancer pain in primary care: Lessons for pharmacists. J. Pain Res. 2014, 7, 163-173. [CrossRef] [PubMed]

28. Axon, D.R.; Patel, M.J.; Martin, J.R.; Slack, M.K. Use of multidomain management strategies by community dwelling adults with chronic pain: Evidence from a systematic review. Scand. J. Pain 2018, 19, 9-23. [CrossRef]

29. Haigh, E.A.; Bogucki, O.E.; Sigmon, S.T.; Blazer, D.G. Depression Among Older Adults: A 20-Year Update on Five Common Myths and Misconceptions. Am. J. Geriatr. Psychiatry 2018, 26, 107-122. [CrossRef]

30. Agency for Healthcare Research and Quality. Survey Background. Available online: https://meps.ahrq.gov/mepsweb/about_ meps/survey_back.jsp (accessed on 9 May 2020).

31. Agency for Healthcare Research and Quality. Download Data Files, Documentation, and Codebooks. Available online: https: / / meps.ahrq.gov/mepsweb / data_stats/download_data_files.jsp (accessed on 9 May 2020).

32. Agency for Healthcare Research and Quality. MEPS HC-201 2017 Full Year Consolidated Data File. Available online: https: //meps.ahrq.gov/data_stats/download_data/pufs/h201/h201doc.pdf (accessed on 9 May 2020).

33. Agency for Healthcare Research and Quality. MEPS HC-201 2017 Full Year Consolidated Data Codebook. Available online: https:/ / meps.ahrq.gov/data_stats/download_data/pufs/h201/h201cb.pdf (accessed on 9 May 2020).

34. Andersen, R.M. Revisiting the Behavioral Model and Access to Medical Care: Does it Matter? J. Health Soc. Behav. 1995, 36, 1-10. [CrossRef] [PubMed]

35. Costanza, A.; Amerio, A.; Radomska, M.; Ambrosetti, J.; Di Marco, S.; Prelati, M.; Aguglia, A.; Serafini, G.; Amore, M.; Bondolfi, G.; et al. Suicidality Assessment of the Elderly with Physical Illness in the Emergency Department. Front. Psychiatry 2020, 11, 558974. [CrossRef] [PubMed] 
36. Fishbain, D.A.; Lewis, J.E.; Gao, J. The Pain Suicidality Association: A Narrative Review. Pain Med. 2014, 15, 1835-1849. [CrossRef] [PubMed]

37. Tang, N.K.Y.; Crane, C. Suicidality in chronic pain: A review of the prevalence, risk factors and psychological links. Psychol. Med. 2006, 36, 575-586. [CrossRef]

38. Calati, R.; Bakhiyi, C.L.; Artero, S.; Ilgen, M.; Courtet, P. The impact of physical pain on suicidal thoughts and behaviors: Meta-analyses. J. Psychiatr. Res. 2015, 71, 16-32. [CrossRef] [PubMed]

39. Hassett, A.L.; Aquino, J.K.; Ilgen, M.A. The Risk of Suicide Mortality in Chronic Pain Patients. Curr. Pain Headache Rep. 2014, 18, 1-7. [CrossRef] [PubMed]

40. Costanza, A.; Baertschi, M.; Richard-Lepouriel, H.; Weber, K.; Berardelli, I.; Pompili, M.; Canuto, A. Demoralization and its relationship with depression and hopeless-ness in suicidal patients attending an emergency department. Int. J. Environ. Res. Public Health 2020, 17, 2232. [CrossRef] [PubMed]

41. Costanza, A.; Baertschi, M.; Richard-Lepouriel, H.; Weber, K.; Pompili, M.; Canuto, A. The Presence and the Search Constructs of Meaning in Life in Suicidal Patients Attending a Psychiatric Emergency Department. Front. Psychiatry 2020, 11, 327. [CrossRef]

42. Costanza, A.; Amerio, A.; Odone, A.; Baertschi, M.; Richard-Lepouriel, H.; Weber, K.; Di Marco, S.; Prelati, M.; Prelati, A.; Prelati, A.; et al. Suicide prevention from a public health perspective. What makes life meaningful? The opinion of some suicidal patients. Acta Biomed. 2020, 91, 128-134. [CrossRef]

43. Costanza, A.; Chytas, V.; Mazzola, V.; Piguet, V.; Desmeules, J.; Bondolfi, G.; Cedraschi, C. The Role of Demoralization and Meaning in Life (DEMIL) in Influencing Suicidal Ideation Among Patients Affected by Chronic Pain: Protocol of a Single-Center, Observational, Case-Control Study. JMIR Res. Protoc. 2020, 9, e24882. [CrossRef]

44. Amstadter, A.B.; Begle, A.M.; Cisler, J.M.; Hernandez, M.A.; Muzzy, W.; Acierno, R. Prevalence and Correlates of Poor Self-Rated Health in the United States: The National Elder Mistreatment Study. Am. J. Geriatr. Psychiatry 2010, 18, 615-623. [CrossRef]

45. Ohrnberger, J.; Fichera, E.; Sutton, M. The relationship between physical and mental health: A mediation analysis. Soc. Sci. Med. 2017, 195, 42-49. [CrossRef]

46. Townley, G.; Terry, R.; Brusilovskiy, E.; Snethen, G.; Salzer, M.S. Associations Between Physical Health Limitations and Community Participation Among People with and without Serious Mental Illnesses. Psychiatr. Serv. 2019, 70, 689-695. [CrossRef]

47. Kwak, Y.; Kim, Y. Health-related Quality of Life and Mental Health of Elderly by Occupational Status. Iran. J. Public Health 2017, 46, 1028-1037.

48. Thielke, S.; Fan, M.-Y.; Sullivan, M.; Unützer, J. Pain Limits the Effectiveness of Collaborative Care for Depression. Am. J. Geriatr. Psychiatry 2007, 15, 699-707. [CrossRef]

49. Karp, J.F.; Zhang, J.; Wahed, A.S.; Anderson, S.; Dew, M.A.; Fitzgerald, G.K.; Weiner, D.K.; Albert, S.; Gildengers, A.; Butters, M.; et al. Improving Patient Reported Outcomes and Preventing Depression and Anxiety in Older Adults With Knee Osteoarthritis: Results of a Sequenced Multiple Assignment Randomized Trial (SMART) Study. Am. J. Geriatr. Psychiatry 2019, 27, 1035-1045. [CrossRef]

50. Foley, D.J.; Vitiello, M.V.; Bliwise, D.L.; Ancoli-Israel, S.; Monjan, A.A.; Walsh, J.K. Frequent Napping Is Associated With Excessive Daytime Sleepiness, Depression, Pain, and Nocturia in Older Adults: Findings From the National Sleep Foundation '2003 Sleep in America' Poll. Am. J. Geriatr. Psychiatry 2007, 15, 344-350. [CrossRef]

51. Brinda, E.M.; Rajkumar, A.P.; Attermann, J.; Gerdtham, U.G.; Enemark, U.; Jacob, K.S. Health, Social, and Economic Variables Associated with Depression Among Older People in Low and Middle Income Countries: World Health Organization Study on Global AGEing and Adult Health. Am. J. Geriatr. Psychiatry 2016, 24, 1196-1208. [CrossRef]

52. Dimidjian, S.; Hollon, S.D.; Dobson, K.S.; Schmaling, K.B.; Kohlenberg, R.J.; Addis, M.E.; Gallop, R.; McGlinchey, J.B.; Markley, D.K.; Gollan, J.K.; et al. Randomized trial of behavioral activation, cognitive therapy, and antidepressant medication in the acute treatment of adults with major depression. J. Consult. Clin. Psychol. 2006, 74, 658-670. [CrossRef] [PubMed]

53. Jacobson, N.S.; Dobson, K.S.; Truax, P.A.; Addis, M.E.; Koerner, K.; Gollan, J.K.; Gortner, E.; Prince, S.E. A component analysis of cognitive-behavioral treatment for depression. J. Consult. Clin. Psychol. 1996, 64, 295-304. [CrossRef] [PubMed]

54. Chen, S.T.; Volle, D.; Jalil, J.; Wu, P.; Small, G.W. Health-Promoting Strategies for the Aging Brain. Am. J. Geriatr. Psychiatry 2019, 27, 213-236. [CrossRef] [PubMed]

55. Wolf, M.; Gazmararian, J.A.; Baker, D.W. Health Literacy and Functional Health Status Among Older Adults. Arch. Intern. Med. 2005, 165, 1946-1952. [CrossRef] [PubMed] 